\title{
Giant endotracheal thrombus: a rare cause of post-operative dyspnea
}

\author{
Özge ÖZTÜRK ${ }^{1}$ \\ Dorina ESENDAĞLI ${ }^{1}$ \\ Emine $\mathrm{YAZICI}^{1}$ \\ Deniz KÖKSAL ${ }^{1}$ \\ Salih Kahraman Ahmet \\ EMRi ${ }^{1}$
}

\footnotetext{
${ }^{1}$ Department of Chest Diseases, Faculty of Medicine, Hacettepe University, Ankara, Turkey

${ }^{1}$ Hacettepe Üniversitesi Tıp Fakültesi, Göğüs Hastalıkları Anabilim Dalı, Ankara, Türkiye
}

Airway obstruction leading to dyspnea/asphyxia can occur in variable conditions which may be either acute or chronic. Chronic causes such as neoplasms, emphysema, pulmonary fibrosis, laryngotracheal scarring and stenosis are usually easy to estimate and diagnose, whereas acute conditions like pulmonary infections, anaphylaxis, asthma or chronic obstructive pulmonary disease (COPD) exacerbations, foreignbody aspiration, inhalation of noxious substances and endotracheal or endobronchial thrombi may not be very obvious to physicians and may result in death if no proper intervention is performed (1). In this paper, we present a case of airway obstruction due to a giant endotracheal thrombuswhich developed postoperatively and discuss the clinical aspects and management.

An 80 year old male patient presented with progressive dyspnea within a period of one week. He had a past history of trauma and surgery for femur head fracture. After hospital discharge he experienced dyspnea and was given enoxaparin at a dose of $0.6 \mathrm{cc}$ twice a day with a preliminary diagnosis of pulmonaryembolism. He was referred to our center for further evaluation. The patient had a tracheostomy as he was operated for larynx cancer 20 years ago. He also had a past history of chronic renal failure, coronary heart disease and was on aspirin $1 \times 100 \mathrm{mg}$ and clopidogrel $1 \times 25 \mathrm{mg}$. At the emergency room, the physicians preferred to perform a ventilation/perfusion (V/P) scintigraphydue to impaired renal function. V/P scintigraphy revealed a low probability for pulmonary thromboembolism. Routine blood chemistry was normal apart from high BUN $(57 \mathrm{mg} / \mathrm{dL})$ and creatinine $(2.18 \mathrm{mg} / \mathrm{dL})$ levels. The arterial blood gas analysis revealed respiratory alkalosis $(\mathrm{pH}: 7.47 \mathrm{mmHg})$, hypoxemia $\left(\mathrm{PaO}_{2}: 49\right.$ $\mathrm{mmHg}$ ) and hypocapnia $\left(\mathrm{PaCO}_{2}: 32 \mathrm{mmHg}\right)$.

The patient hospitalized in the internal medicine ward. On admission, he was orthopneic, dyspneic and tachypneic. The supraclavicular fossa was retracted bilaterally in every single inspiration. With the preliminary diagnosis of a tracheal obstruction, a

\section{Yazışma Adresi (Address for Correspondence)}

Dr. Dorina ESENDAĞLI

Hacettepe Üniversitesi Tıp Fakültesi, Göğüs Hastalıkları Anabilim Dalı, ANKARA - TURKEY

e-mail: dorinarama@hotmail.com 
thorax computed tomography without contrast was performed. A segmental atelectasis in left lower lobe and soft tissue/thick secretions starting from the distal trachea until the left main bronchus entrance were noted (Figure 1). Flexible bronchoscopy through tracheostomy was performed and a giant hard thrombus obstructing the lumen of trachea was observed. Saline lavage and suctioning was the first attempt to remove the thrombus which was unsuccessful. The next step was the forceps extraction in a piecemeal fashion and the forceps and bronchoscope pulled together because of the big size of thrombus, but this technique also failed to relieve the patients symptoms. The patient was consulted to the Otolaryngology department. By the help of a curved ended surgical portegue inserted through tracheostomy and bronchoscope guidance a $10 \mathrm{~cm}$ hard tracheal thrombus was removed (Figure 2). After the thrombus excision a remarkable improvement of oxygen saturation and the overall patient's clinical condition was observed. The drugs enhancing the tendency to bleed were discontinued. During the follow up recurrence of small sized thrombi which were thought to be secondary to tracheal mucosal bleeding due to anticoagulant treatment and chronic kidney failure was noted and bronchoscopy was repeated to clear off the remaining.

In the literature, there are only a few case reports about asphyxia and dyspnea due to endotracheal thrombus. The first reported case of endobronchial obstruction due to blood clot was reported in 1929, which describes a case with tuberculosis who developed acute respiratory distress 3 days after onset of hemoptysis (2). Other causes of blood clot formation in airway system include bronchiectasis, mitral stenosis, pulmonary infarction, pulmonary arteriovenous malformation, sarcoidosis, bronchial carcinoma, and inthrathoracic trauma (3). Interventions to the airway system like transbronchial biopsy, tracheostomy, traumatic intubation, mucosal damage/lacerations due to aspiration catheters can also lead to formation of thrombus within the airway

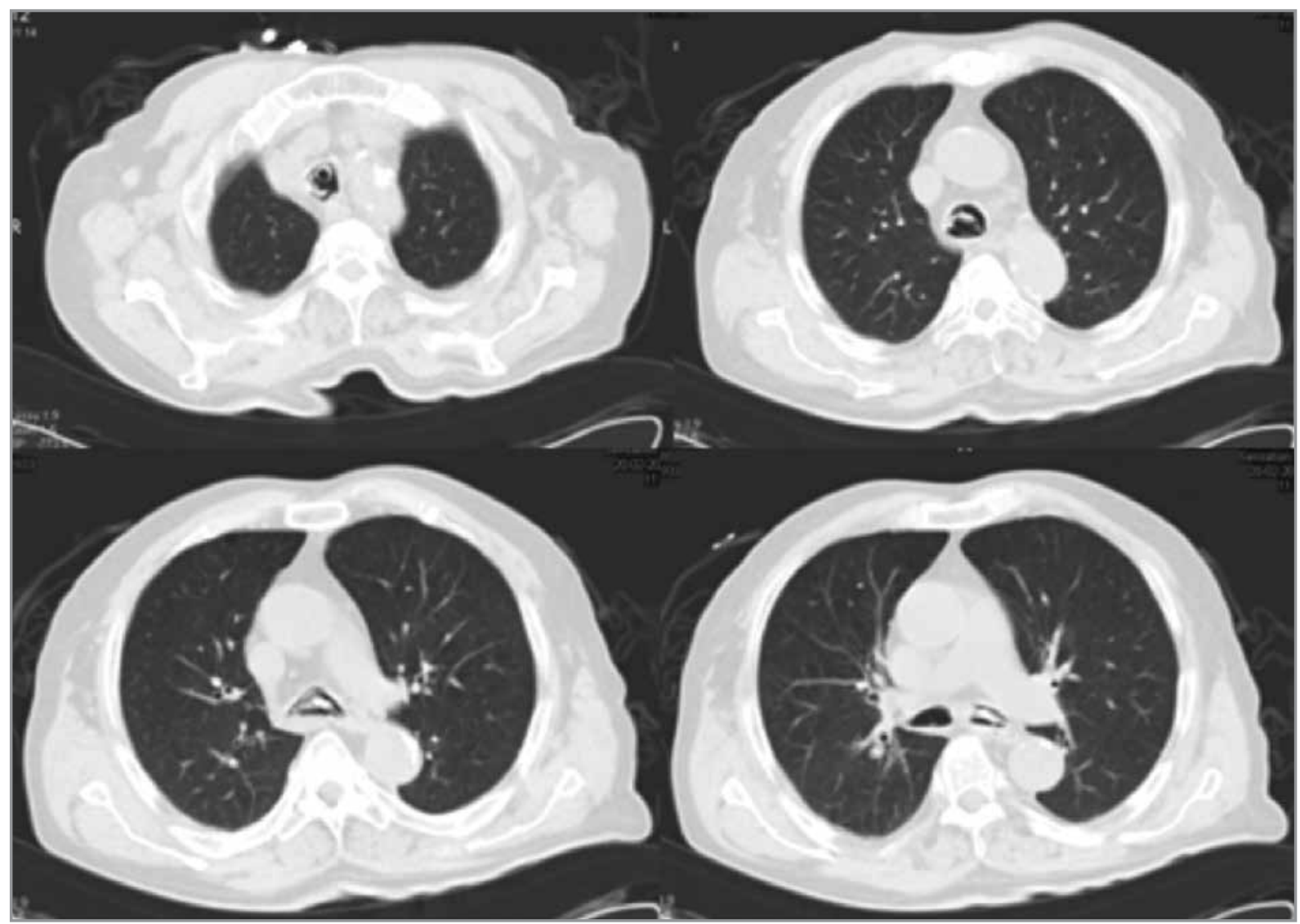

Figure 1. Computed tomography of thorax demonstrating soft tissue/thick secretions starting from the distal trachea until the left main bronchus entrance. 


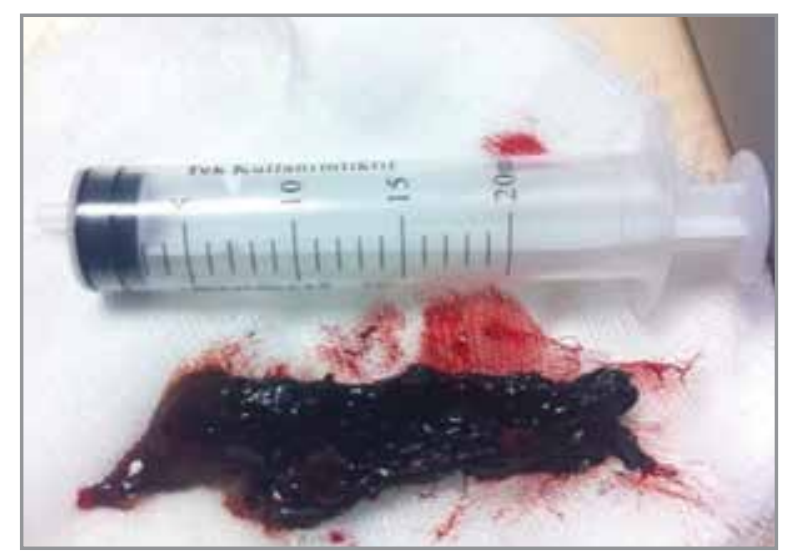

Figure 2. Extracted giant endotracheal thrombus.

system (4). A history of endobronchial bleeding can help in diagnosis, but according to Arney et al $30 \%$ of cases reported in literature had no evidence of preceding hemoptysis. These cases were associated with prolonged mechanical ventilation or tracheostomy placement (3). Our case had multiple risk factors which can lead to thrombus formation such as: tracheostomy placement, endotracheal intubation during surgery and post-operative anticoagulant treatment usage which all together contributed to mucosal bleeding and thrombus formation. Although one of the most common causes of post-operative dyspnea is thought to be pulmonary thromboembolism, traumatic mucosal damage and anticoagulant treatment usage which can lead to endotracheal thrombus formation should be kept in mind while evaluating patients with especially inspiratory dyspnea and management should be carefully done in order to avoid iatrogenic causes (5). Once the endobronchial blood clot is diagnosed efforts for its removal should be done immediately. These efforts consist of primarily lavage, suctioning and forceps extraction by a flexible bronchoscope (6). If these procedures are not successful rigid bronchoscopy, Fogarty catheter usage or topical thrombolysis with streptokinase or urokinase may be applied (7-9). In our case a curved ended surgical portegue inserted through tracheostomy under bronchoscope guidance was used to remove the endothraceal thrombus. This procedure can be effective especially in cases were thrombus is easily reached by such instruments. However close monitoring is essential after the removal of the clot. It should be kept in mind that there is always a risk of re-bleeding leading to the recurrence of thrombus.

\section{REFERENCES}

1. Collins KA, Presnell SE. Asphyxia by tracheobronchial thrombus. Am J Forensic Med Pathol 2005;26:327-9.

2. Wilson IL. Hemoptysis in tuberculosis followed by massive pulmonary atelectasis. Am Rev Tuberc 1929;19:310-3.

3. Arney KE, Judson MA, Sahn SA. Airway obstruction arising from blood clot. Three reports and a review of the literature. Chest 1999;115:293-300.

4- Pzanin L, Misak VB, Goreta N, Marekovic Z, Ptrovecki V. latrogenic tracheal laceration causing asphyxia. J Forensic Sci 2008;53:1185-7.

5- Cukic V. The pulmonary thromboembolism as a risk of surgical treatments and the role of anticoagulant prophylaxis. Mater Sociomed 2014;26:303-5.

6- Sprung J, Bourke DL, Harrison C. Endotracheal tube and tracheobronchial obstruction as causes of hypoventilation with high inspiratory pressures. Chest 1994; 105:550-2.

7- Allen RP, Siefkin AD. Emergency airway clot removal in acute hemorrhagic respiratory failure. Crit Care Med 1987; 15:985-6.

8- Vajo Z, Parish JM. Endobronchial thrombolysis with streptokinase for airway obstruction due to blood clots. Mayo Clin Proc 1996;71:595-6.

9- Botnick W, Brown H. Endobronchial urokinase for dissolution of massive clot following transbronchial biopsy. Chest 1994;105:953-4. 